\title{
Effect of interictal epileptiform EEG discharges on cognitive functions in epileptic children
}

Kamel M. Hewedi ${ }^{1}$, Wael O. Mohamed ${ }^{1}$, Amr A. Mostafa ${ }^{2}$, Mohamed A. Zaki ${ }^{1}$, Fathy M. Mansour ${ }^{1}$

${ }^{1}$ Department of Neurology, ${ }^{2}$ Department of Radiology, Faculty of Medicine, Al-Azhar University, Cairo, Egypt.

Corresponding author: Fathy M. Mansour; Mobile: 01096946464; Email: dr.fathy.mansour@gmail.com

\begin{abstract}
Background: Epilepsy is a chronic disorder of the brain that affects people of all ages Neuropsychological impairment is an important comorbidity of chronic epilepsy in the majority of children with epilepsy. interictal epileptiform EEG discharges may present as a complicating factor in spite of being seizure free. In a group of children with interictal EEG discharges there is sudden and unexpected decline of school performance as the first symptom of epilepsy. Consequently, accumulating cognitive impairment, and even a decline in IQ scores, is reported in epileptic children with frequent episodes with epileptiform EEG discharges.

Aim of the Work: To evaluate the possible relationship between interictal EEG discharge and cognitive function in a sample of Egyptian epileptic children.

Patients and Methods: The ethical approval was obtained from the Hospital Ethical Research Committee. Each patient and/or parents entering the study signed an informed consent. This study was conducted on 140 children selected from Epilepsy Outpatient Clinic of Al-Azhar University Hospitals during a period of two years starting from June 2016 untill June 2018. A specialized pediatric neurology sheet was taken. EEG and cognitive assessment of epileptic patients with and without epileptiform EEG discharges using Stanford-Binet intelligence scale and P300 by ERP were performed to each patient two times 3 months in between.

Results: we found that patients with frequent IEDs had high mean P300 latency and low IQ when compared to patients with infrequent and normal EEG examination. In addition, the mean p300 latency significantly reduced with rising in IQ (more improvement in cognitive function) after disappearance of IED in some patients.

Conclusion: Interictal epileptiform EEG discharge had an additional effect on cognitive function especially if generalized and of high frequency. This effect might be often underestimated and might accumulate, and have a severe cognitive impact. So, treatment of epileptic patients should put in concern reduction or even treatment of IEDs as controlling of these IED lead to improvement of cognition.
\end{abstract}

Keywords: Epilepsy, interictal epileptiform discharge, cognition.

\section{INTRODUCTION}

Epilepsy is a chronic disorder of the brain that affects people of all ages. It is the most common serious neurological condition in the world, and an important cause of mortality and disability in developing countries ${ }^{(1)}$.

Approximately 50 million people worldwide have epilepsy, making it one of the most common neurological diseases globally ${ }^{(2)}$.

A long and rich history of research has characterized relationships between cognitive function and epilepsy ${ }^{(3)}$.

Many of these cognitive deficits are related directly to the brain disorder underlying the epilepsy syndrome. However, in other types of epilepsy, the epileptic seizures and/or epileptiform activity can be the dominant factor ${ }^{(4)}$.

Epilepsy, its underlying cause or treatment may not stop all development. It may simply cause cognitive development to occur more slowly or less fully than it would have done without the epilepsy (5).
In the majority of children with epilepsy, epileptiform interictal EEG discharges may present as a complicating factor in spite of being seizure free ${ }^{(6)}$.

Interictal epileptiform activity is defined by spikes and sharp waves, with or without slow waves $^{(7)}$.

Interictal epileptiform EEG discharges also have cognitive effects, although these effects are generally reported to be reversible when these discharges are controlled, their impact on daily life may be greater than suspected, especially when the effects are not recognized or when the discharges persist for years. In a group of children with interictal EEG discharges, there is sudden and unexpected decline of school performance as the first symptom of epilepsy ${ }^{(8)}$.

Consequently, accumulating cognitive impairment, and even a decline in IQ scores, is reported in epileptic children with frequent episodes with epileptiform EEG discharges ${ }^{(9)}$. 
Until now there is no universal agreement exists about the need for treatment of such interictal discharges ${ }^{(6)}$.

\section{AIM OF THE WORK}

The aim of this work is to evaluate the possible relationship between interictal EEG discharges and cognitive function in a sample of Egyptian epileptic children.

\section{PATIENTS AND METHODS}

The ethical approval was obtained from the Hospital Ethical Research committee. Each patient and/or parents entering the study signed an informed consent.

This study was conducted on 140 children selected from Epilepsy Outpatient Clinic of AlAzhar University Hospitals during a period of two years starting from June 2016 until June 2018. They were divided into two groups:

\section{Patients group:}

Included 100 epileptic children. They were 53 males (53\%) and 47 females (47\%). Their ages ranged between 8 to 18 years old with a mean of $(12.32 \pm 2.96$ years). The patients were fulfilling the following inclusion and exclusion criteria:

Inclusion criteria: Epileptic children diagnosed according to ILAE (2014). Age: from 8 to 18 years old. Controlled cases (individual who remained without seizures for either 3 times the prior to the inter-seizure interval or 1 year). No change in AEDS in the previous year. Children with normal MRI brain.

Exclusion criteria: Children with mental handicap or malignant epilepsy syndromes with etiology that may affect cognitive function (such as LennoxGastaut syndrome). Children with comorbid diagnoses of Attention Deficit/Hyperactivity. Children with developmental disabilities (developmental delay). Drugs which may affect cognitive function other than AEDS.

Based on EEG findings, patients' group were divided into 2subgroups based on the presence of interictal epileptiform EEG discharges IED (abnormal group) or absence of these discharges (normal group).

\section{Control group:}

Included (40) child matched with the same age (ranged between 8-18 years old) and sex with patients' group. They were 22 males (55\%) and 18 females (45\%). All subjects were non-epileptic children without histories of (i) any initial precipitating event (e.g. simple or complex febrile seizures); (ii) any seizure or seizure-like episode; (iii) diagnosed neurological disease; or (iv) other family history of a first-degree relative with epilepsy or febrile convulsions.

All patients were subjected to the following: History taking according to pediatric neurology sheet and included: Duration of epilepsy. Type of seizure. Seizure frequency. Time of last seizure. Family history of epilepsy. Types, numbers and duration of AEDS. Full general examination. Full neurological examination. MRI brain (epilepsy protocol) to exclude any structural abnormality. Electro encephalogram (EEG): EEG exam was done. The patient was seated relaxed and lie comfortable at $45^{\circ}$ on the couch. The electrodes were placed on the scalp after being cleaned with rectified spirit and according to the international 10-20 system held in place. Twenty-one electrodes used, then we asked the patient to relax and close his eyes. The recording period continued for 30 minutes during which we used hyperventilation (3 minutes deep breath $17 \mathrm{C} /$ minutes) and photic stimulation as activation procedures unless contraindicated. The recorded EEG waves were averaged, amplified and filtered with band frequencies of $0.5-30 \mathrm{~Hz}$, sweep speed $15 \mathrm{sec}$ d/page and sensitivity of $50 \mathrm{uv} / \mathrm{cm}$. The EEG trace was saved for reanalysis.

The EEG obtained after 30 mints of recording was categorized into two groups according to presence of IEDs: Normal: patients with normal EEG record (without IED). Abnormal: patients with abnormal EEG record (with IED). IEDs were defined as spike or sharp wave discharges that clearly stood out from the background rhythms, with or without an after going slow wave. The localization and frequency of interictal epileptiform activity will be determined.

\section{IQ using Stanford Binet test:}

The Stanford-Binet intelligence scale is a standardized test that assesses intelligence and cognitive abilities in children and adults. The factors assessed in the test are: verbal reasoning, quantitative reasoning, abstract/visual reasoning, and working memory. Each is assessed in two separate domains, verbal and nonverbal. The test covers 15 subtests, including vocabulary, 
comprehension, verbal absurdities, pattern analysis, matrices, paper folding and cutting, copying, quantitative, number series, equation building, memory for sentences, memory for digits, memory for objects, and bead memory. All test subjects took an initial vocabulary test, which along with the subject's age, determines the number and level of subtests to be administered. Total testing time was 45-90 minutes, depending on the subject's age and the number of subtests given. Raw scores were based on the number of items answered and were converted into a standard age score corresponding to age group, similar to an IQ measure.

\section{Event-related potentials (ERPs) for p300:}

An event-related potential (ERP) is a measured brain response that is the direct result of a specific sensory, cognitive, or motor event. ERPs were measured by electroencephalogram (EEG) and represent any stereotyped electrophysiological response to a stimulus. The study of the brain in this way provided a noninvasive means of evaluating brain function in patients with psychological, neurological and cognitive dysfunctions.

The P300 latency is considered to reflect stimulus evaluation time, the process of selective attention, and/or the updating of working memory. The P300 is a late component of ERP occurring at a latency of approximately $300 \mathrm{~ms}$ after presentation of the target stimulus and has provided a useful tool for noninvasively assessing cognitive functions in humans.

P300 tasks generally use auditory stimulation but are sometimes designed with visual or somatosensory stimulations.

\section{A) Stimulus and recording parameters:}

P300 was recorded using an oddball paradigm. Two tones were presented in a random series at a rate of $0.5 / \mathrm{sec}$. A frequent tone $(1000$ $\mathrm{Hz}$ ) was presented in $80 \%$ of testing time, and a target tone $(2000 \mathrm{HZ})$ was presented randomly in $20 \%$ of testing time. The two stimuli had a rise/ fall time of $50 \mathrm{msec}$. and a plateau duration of 200 msec. The stimuli were presented at an intensity of $60 \mathrm{~dB}$ SL. An intensity of a fixed sensation had to be used as P300 parameters may be affected with intensity of the stimuli.

One hundred stimuli were collected in each run. Stimuli were presented monaurally (right and left separately) with distracting sound in the other ear. The neurophysiological activity was filtered from $0.1-30 \mathrm{~Hz}$ and displayed on $750 \mathrm{msec}$. prestimulus recording period was used as a base line for further analysis of P300 amplitude.

\section{b) Electrode Montage:}

The responses were obtained with the active electrode at CZ, (according to the international 10-20 system of electrode placement) referenced to the ipsilateral mastoid. The ground electrode was placed on the contra-lateral mastoid. The electrode impedance was kept below five Kohms.

\section{c) Procedure:}

Electrode sites were cleaned with alcohol. For the vertex electrode site, the hair was parted as the scalp was visible and the area was cleaned using a cotton pad soaked in alcohol. The $\mathrm{Cz}$ electrode was pressed onto the prepared scalp site and secured in its place with a cotton ball. The silver cup electrodes were filled with gel, applied to both mastoids and kept in place by adhesive plaster.

All subjects were tested while sitting comfortably with eyes open. The earphones were placed on their head. They received instructions to ensure their understanding to the task. The stimulus was first presented to the subjects without recording and they were instructed to discriminate between the two stimuli (frequent and in frequent). After subject could identify both stimuli well, he was instructed to be mentally attentive and count the number of rare" high pitched" stimuli and report this number after each block of trails. The accepted percent of correct identification of the number of target stimuli was judged to be $90 \%$ or more. If lesser percentage were obtained, retest after training was done.

\section{d) Response analysis and measurement:}

Analysis of the P300 had involved the waveform identification, amplitude, latency and number of peaks of P300.

\section{Waveform identification:}

Identification of the location of the P300 as the positive peak or "series of peaks" occurring at a latency of approximately $300 \mathrm{~ms}$. after presentation of the target stimulus. it might be with single, double or multiple peaks. 


\section{P300 Latency:}

It is defined as the difference in milliseconds between the presentation of the infrequent target stimulus and the most prominent positive peak" or series of peaks. If a single peak was present after $250 \mathrm{msec}$. it was identified as the P300 and in this condition the latency was taken at the middle of that peak. In cases of double or multiple peaks of $\mathrm{P} 300$ wave intersect procedure was used.

\section{P300 Amplitude:}

A 50-msec. pre-stimulus baseline was used. The P300 amplitude was identified as the maximum voltage within the previous specified latency range relative to the baseline.

Most previous studies have described prolonged P300 latencies and no significant reductions in P300 amplitude among patients with epilepsy.

EEG exam, IQ and cognitive function test (P300) were done for each patient two time at three months' interval period, and one time for control group.

\section{Statistics:}

Statistical presentation and analysis of the present study was conducted, using the mean, standard deviation, unpaired student t-test, the Wilcoxon tests, linear correlation coefficient, analysis of variance [ANOVA] tests, paired t-test and chi-square by SPSS V17.

Mean X: to measure a central value for a group of data.

Standard deviation $[\mathrm{SD} \pm]$ : to measure the variations within a group.

Student t-test: to test for significant difference between two samples means.

Chi-square test: to test statistically significant relations between different qualitative data.

The Wilcoxon tests: It's used to test the significance of the difference between two samples (paired or unpaired observations), when the distribution of these samples is not normal.

\section{RESULTS}

Table (1): Comparison between control group and patients' group regarding IQ and P300 latency at visit 1 (V1).

\begin{tabular}{|c|c|c|c|c|c|c|}
\hline & $\begin{array}{c}\text { Control } \\
\text { group }\end{array}$ & $\begin{array}{l}\text { Patients } \\
\text { group }\end{array}$ & \multirow{2}{*}{ Test value• } & \multirow{2}{*}{ P-value } & \multirow{2}{*}{ Sig. } \\
\hline & & No. $=40$ & No. $=100$ & & & \\
\hline \multirow{3}{*}{ IQ V1 } & Mean \pm SD & $95.65 \pm 4.17$ & $87.32 \pm 7.35$ & \multirow{3}{*}{6.735} & \multirow{3}{*}{0.001} & \multirow{3}{*}{ HS } \\
\hline & Range & $89-105$ & $71-110$ & & & \\
\hline & Range & $89-105$ & $70-105$ & & & \\
\hline \multirow{3}{*}{ P300 latency V1 } & Mean \pm SD & $310.75 \pm 8.95$ & $360.94 \pm 15.55$ & \multirow{3}{*}{-19.153} & \multirow{3}{*}{0.001} & \multirow{3}{*}{ HS } \\
\hline & Range & $295-327$ & $320-387$ & & & \\
\hline & Range & $295-327$ & $320-395$ & & & \\
\hline
\end{tabular}

There were high significant differences between patients' group and control group as regards IQ and P300 latency in visit 1 (P-value < 0.001).

Table (2): Comparison between normal and abnormal EEG patients at visit 1 regarding IQ and P300 latency.

\begin{tabular}{|c|c|c|c|c|c|c|}
\hline & \multicolumn{2}{|c|}{ EEG V1 } & \multirow{3}{*}{ Test value • } & \multirow{3}{*}{ P-value } & \multirow{3}{*}{ Sig. } \\
\hline & & \multirow{2}{*}{$\begin{array}{c}\text { Normal } \\
\text { No. }=55\end{array}$} & \multirow{2}{*}{$\begin{array}{c}\text { Abnormal } \\
\text { No. }=45\end{array}$} & & & \\
\hline & & & & & & \\
\hline IQ V1 & \begin{tabular}{|l} 
Mean \pm SD \\
Range
\end{tabular} & $\begin{array}{c}87.98 \pm 5.75 \\
75-105\end{array}$ & $\begin{array}{c}86.51 \pm 8.94 \\
71-110\end{array}$ & 0.995 & 0.322 & NS \\
\hline P300 latency V1 & $\begin{array}{l}\text { Mean } \pm \text { SD } \\
\text { Range }\end{array}$ & $\begin{array}{c}351.87 \pm 14.19 \\
320-382\end{array}$ & $\begin{array}{c}372.02 \pm 8.29 \\
357-387\end{array}$ & -8.416 & 0.001 & HS \\
\hline
\end{tabular}

There was high statistically significant difference between patients with normal and patients with abnormal EEG (IED) in V1 as regard P300 and no significance concerning the IQ.

Table (3): Comparison between normal and abnormal EEG patients at visit 2 regarding IQ and P300 latency.

\begin{tabular}{|c|c|c|c|c|c|c|}
\hline & \multicolumn{2}{|c|}{ EEG V2 } & \multirow{3}{*}{$\begin{array}{c}\text { Test } \\
\text { value• }\end{array}$} & \multirow{3}{*}{$\begin{array}{c}\text { P- } \\
\text { value }\end{array}$} & \multirow{3}{*}{ Sig } \\
\hline & & \multirow{2}{*}{$\begin{array}{c}\text { Normal } \\
\text { No. }=64\end{array}$} & \multirow{2}{*}{$\begin{array}{c}\text { Abnormal } \\
\text { No. }=36\end{array}$} & & & \\
\hline & & & & & & \\
\hline IQ V2 & $\begin{array}{l}\text { Mean } \pm \text { SD } \\
\text { Range }\end{array}$ & $\begin{array}{c}86.69 \pm 5.81 \\
73-105\end{array}$ & $\begin{array}{c}81.69 \pm 7.79 \\
70-98\end{array}$ & 3.641 & 0.001 & HS \\
\hline $\begin{array}{l}\mathrm{P} 300 \\
\text { latency V2 }\end{array}$ & $\begin{array}{l}\text { Mean } \pm \text { SD } \\
\text { Range }\end{array}$ & $\begin{array}{c}352.98 \pm 14.20 \\
320-384\end{array}$ & $\begin{array}{c}381.58 \pm 5.68 \\
370-395\end{array}$ & -11.551 & 0.001 & HS \\
\hline
\end{tabular}

There was high statistically significant difference between patients with normal EEG and patients with abnormal EEG(IED) in V2 as regards IQ and P300.

Table (4): Comparison between visit 1 and visit 2 regarding IQ and P300 latency among patients with normal EEG at visit1.

\begin{tabular}{|c|c|c|c|c|c|c|}
\hline \multicolumn{2}{|c|}{$\begin{array}{c}\text { EEG V1 } \\
\text { (Normal) }\end{array}$} & Visit 1 & Visit 2 & $\begin{array}{c}\text { Test } \\
\text { value• }\end{array}$ & P-value & Sig. \\
\hline IQ & $\begin{array}{c}\text { Mean } \pm \text { SD } \\
\text { Range }\end{array}$ & $\begin{array}{c}87.98 \pm 5.75 \\
75-105\end{array}$ & $\begin{array}{c}87.18 \pm 5.49 \\
73-105\end{array}$ & 1.032 & 0.17 & NS \\
\hline P300 latency & $\begin{array}{c}\text { Mean } \pm \text { SD } \\
\text { Range }\end{array}$ & $\begin{array}{c}351.87 \pm 14.19 \\
320-382\end{array}$ & $\begin{array}{c}351.20 \pm 14.43 \\
320-384\end{array}$ & 1.291 & 0.15 & NS \\
\hline
\end{tabular}

$\because$ Paired t-tes 
There was no significant difference between visit 1 and visit 2 regarding IQ and P300 latency among patients with normal EEG at visit1.

Table (5): Comparison between visit 1 and visit 2 regarding IQ and P300 latency among patients with abnormal EEG at visit 1.

\begin{tabular}{|c|c|c|c|c|c|c|}
\hline \multicolumn{2}{|c|}{ EEG V1 (Abnormal) } & Visit 1 & Visit 2 & Test value• & P-value & Sig. \\
\hline IQ & $\begin{array}{c}\text { Mean } \pm \text { SD } \\
\text { Range }\end{array}$ & $\begin{array}{c}86.51 \pm 8.94 \\
71-110\end{array}$ & $\begin{array}{c}82.09 \pm 7.62 \\
70-100\end{array}$ & 12.372 & 0.001 & HS \\
\hline P300 latency & $\begin{array}{c}\text { Mean } \pm \text { SD } \\
\text { Range }\end{array}$ & $\begin{array}{c}372.02 \pm 8.29 \\
357-387\end{array}$ & $\begin{array}{c}378.04 \pm 9.05 \\
355-395\end{array}$ & -3.377 & 0.002 & HS \\
\hline
\end{tabular}

$\bullet:$ Paired t-test

There was high significant difference between visit 1 and visit 2 regarding IQ and P300 latency among patients with abnormal EEG at V1.

Table (6): Comparison between generalized and focal IED regarding IQ and P300 latency in visit 1.

\begin{tabular}{|c|c|c|c|c|c|c|}
\hline & $\begin{array}{l}\text { Generalized } \\
\text { IED }\end{array}$ & Focal IED & \multirow{2}{*}{$\begin{array}{c}\text { Test } \\
\text { value }\end{array}$} & \multirow{2}{*}{$\begin{array}{c}\text { P- } \\
\text { value }\end{array}$} & \multirow[t]{2}{*}{ Sig } \\
\hline & & No. $=27$ & No. $=18$ & & & \\
\hline \multirow{2}{*}{ IQ V1 } & $\begin{array}{c}\text { Mean } \pm \text { SD } \\
\text { Range }\end{array}$ & $\begin{array}{c}83.44 \pm 8.16 \\
71-105\end{array}$ & $\begin{array}{c}91.11 \pm 8.22 \\
80-110\end{array}$ & \multirow{2}{*}{-3.077} & \multirow{2}{*}{0.004} & \multirow{2}{*}{ HS } \\
\hline & Range & $70-98$ & $76-100$ & & & \\
\hline \multirow{2}{*}{$\begin{array}{c}\mathrm{P} 300 \\
\text { latency V1 }\end{array}$} & $\begin{array}{c}\text { Mean } \pm \text { SD } \\
\text { Range }\end{array}$ & $\begin{array}{c}371.33 \pm 8.67 \\
357-385\end{array}$ & $\begin{array}{c}373.06 \pm 7.81 \\
360-387\end{array}$ & \multirow{2}{*}{-0.678} & \multirow{2}{*}{0.501} & \multirow{2}{*}{ NS } \\
\hline & Range & $365-393$ & $355-395$ & & & \\
\hline
\end{tabular}

There was high statistically significant difference between generalized and focal IED regarding IQ and no significant difference as regard P300 latency in visit 1.

Table (7): Comparison between frequency of IED $(<1 \%$ of time and $>1 \%$ of time) regarding IQ and P300 latency in visit 1 :

\begin{tabular}{|c|c|c|c|c|c|c|}
\hline & & $<1 \%$ of time & $>1 \%$ of time & Test value & P-vaule & Sig. \\
\hline \multirow{3}{*}{ IQ V1 pt } & Mean \pm SD & $92.54 \pm 7.05$ & $79.62 \pm 5.02$ & \multirow{3}{*}{6.988} & \multirow{3}{*}{\begin{tabular}{|l|l|}
0.001 \\
\end{tabular}} & \multirow{3}{*}{ HS } \\
\hline & Range & $84-110$ & $71-87$ & & & \\
\hline & Range & $80-100$ & $70-82$ & & & \\
\hline \multirow{3}{*}{$\begin{array}{l}\text { P300 latency } \\
\text { V1 pt }\end{array}$} & Mean \pm SD & $371.33 \pm 8.07$ & $372.81 \pm 8.66$ & \multirow{3}{*}{-0.591} & \multirow{3}{*}{\begin{tabular}{|l|l}
0.557 \\
\end{tabular}} & \multirow{3}{*}{ NS } \\
\hline & Range & $358-387$ & $357-387$ & & & \\
\hline & Range & $355-395$ & $360-393$ & & & \\
\hline
\end{tabular}

There was high statistically significant difference between patients with IED $>1 \%$ and $<1 \%$ of time of EEG recording regarding IQ and no significant difference as regard P300 latency in visit 1.

Table (8): Comparison between visit 1 and visit 2 regarding IQ and P300 latency among 9 patients with changed EEG:

\begin{tabular}{|c|c|c|c|c|c|c|}
\hline \multirow{2}{*}{\multicolumn{2}{|c|}{ EEG changed in V2 }} & Visit 1 & Visit 2 & \multirow{3}{*}{\begin{tabular}{|c|} 
Test value• \\
5.813
\end{tabular}} & \multirow{3}{*}{\begin{tabular}{|c|} 
P-value \\
0.001
\end{tabular}} & \multirow{3}{*}{\begin{tabular}{|l} 
Sig. \\
HS
\end{tabular}} \\
\hline & & \multirow{2}{*}{\begin{tabular}{|c|} 
No. $=9$ \\
$83.67 \pm 7.09$ \\
$76-100$
\end{tabular}} & No. $=9$ & & & \\
\hline IQ & $\begin{array}{l}\text { Mean } \pm \text { SD } \\
\text { Range }\end{array}$ & & $\begin{array}{c}88.22 \pm 7.73 \\
80-105\end{array}$ & & & \\
\hline P300 latency & $\begin{array}{l}\text { Mean } \pm \text { SD } \\
\text { Range }\end{array}$ & $\begin{array}{c}379.11 \pm 3.92 \\
375-387\end{array}$ & $\begin{array}{c}363.89 \pm 5.21 \\
355-372\end{array}$ & 15.953 & 0.001 & HS \\
\hline
\end{tabular}

•: Paired t-test
There was high statistically significant difference between visit 1 and visit 2 regarding IQ and P300 latency among 9 patients with changed EEG.

\section{DISCUSSION}

This study assessed cognitive function in epileptic patients with and without epileptiform EEG discharges and compared these to one another in two visits 3 months in between using a nonsimultaneous data collection strategy to minimize artifact that could be occurred with simultaneousrecording conditions and to simulate the use of routine EEG results as predictors of neuropsychological impairments.

Epileptiform EEG discharges can be defined as spike or sharp wave discharges that stood out from the background rhythms, with or without an after going slow wave.

The average full-scale IQ in patients' group was $(87.32 \pm 7.35)$ in Visit 1 . This was low in comparison with control group, which was $(95.65$ \pm 4.17 ). This relatively low value was consistent with results of a study of O'Leary $\boldsymbol{e t}$ al. ${ }^{(10)}$ describing performance on the WISC III in children with epilepsy.

In this study patients with normal EEG performed better in cognitive function tests (IQ and P300) than patients with abnormal EEG (in whom IED were presented) both in visit 1 and visit 2. But, when patients with normal EEG were assessed again in visit 2 by cognitive tests (IQ and P300), there were no significant difference between the two visits. However, patients with abnormal EEG showed deterioration in their cognitive functions in visit 2 that was evident by decreased mean IQ from $(86.51 \pm 8.94)$ in Visit 1 to $(82.09 \pm 7.62)$ in visit 2 . In addition, there was increased mean P300 latency from $(372.02 \pm 8.29)$ in visit 1 to $(378.04 \pm 9.05)$ in visit 2 in spite of the presence of the same other epilepsy variables between two groups (frequency of seizure, duration of illness and type and numbers of AEDs) as there was no significant differences between two groups as regard other epilepsy variables. So, epileptiform discharges had an additional effect on cognitive function in this study and this was in line with Jost $\boldsymbol{e t}$ al. ${ }^{(9)}$ and near finding of Aldenkamp et al. (11) who found transient cognitive impairment during discharge and not in the periods before or after it, but they 
carried out EEG and cognitive tests simultaneously and did not follow their patients again.

It is unclear why epileptiform EEG discharges affect cognitive functioning, but apparently some of these discharges may disrupt central information processing similar to seizures. In addition, this might be related to the fact that at cellular level since epileptiform discharges generating neurons exhibit increased susceptibility to premature death. So, early detection of IEDs and appropriate treatment can prevent further neuronal damage $^{(12)}$.

Of interest, there were 9 patients in this study whose EEG showed presence of IED in visit 1. On follow up in visit 2 their EEG became normal after proper treatment with AEDs. These patients showed significant reduction in mean P300 latency, rise in mean IQ as compared to their mean P300 latency and mean IQ in visit 1.

So, as the IEDs presents, P300 latency values increased and IQ decreased which mean a reduction in cognitive function. Besides, as the frequency of IEDs were reduced or the record became normal, P300 latency reduced and IQ raised, which indicated improvement in cognitive function. This was near finding of Shymaa $\boldsymbol{e t}$ al. (13) who found improvement of cognitive function in epileptic patients after proper control of these patients clinically and by EEG, but they assessed the patients in four visits, three months in between.

These results suggest that treatment of epileptic patients should put in concern reduction or even treatment of IEDs since it affects cognitive function and it may cause transient cognitive impairment and behavioral as well as psychological problems especially in children with epilepsy, which itself may contribute to the general longterm risk for cognitive impairment in epilepsy ${ }^{(14)}$.

In addition, as the dose of AEDs adjusted according to EEG results, the frequency of IEDs declined with more control of seizure and improvement of cognitive functions. These results agreed with results of Binnie ${ }^{(6)}$ in his study about treatment of patients with epilepsy in view of EEG monitor. Also, he found that after 6 months of treatment with regular AEDs, $75 \%$ of his patients showed good clinical control and $61.5 \%$ of them showed normal EEG record but he did not assess cognitive function. Although, some other studies showed no relation between clinical control of epilepsy and EEG findings as Hirokazu ${ }^{(15)}$ but his study was conducted only on patients with mesial temporal sclerosis, and this group of deep seated foci are difficult to be recorded by scalp electrodes. Also, those patients had a structural lesion that may affect the results (act as source for continues IEDs). In our study we selected patients with normal MRI scan to exclude any possible structural brain abnormalities.

These results suggested that proper choose of AEDs according to seizure type and regular administration, beside adjustment of the dose according to clinical condition of the patient will help greatly in reduction of IEDs ${ }^{(16)}$. Besides, the management of epilepsy could be aided with continuous EEG monitor for epileptic discharge and clinical as well as EEG control of epilepsy and IEDs, which if combined together will achieve good control of both clinical and subclinical seizures ${ }^{(17)}$.

\section{As regards to localization of IED:}

children with generalized IED showed more neuropsychological impairment than children with focal IED and this was in line with Aldenkamp et al. (18) who found that cognitive impairment was more common during prolonged (> 3s) generalized activity than during focal activity. However, this disagreed with Jennifer et al. ${ }^{(19)}$ who found that children with generalized EA did not show more neuropsychological impairment than children with focal EA. This finding might be related to seizure type. Approximately, half of the sample with generalized seizures were diagnosed with absence seizures, which are considered to be more benign than tonic-colonic seizures ${ }^{(20)}$. Also, disagreed with Aldenkamp et al. ${ }^{(11)}$ who found that the effects occurred only for generalized discharges and not for focal discharges. However, there seemed to be an underlying factor that was related to the type of epilepsy.

\section{Concerning frequency of IED:}

When the group with epileptiform EEG discharges $<1 \%$ of the time was compared to those with epileptiform EEG discharges $>1 \%$ of the time, statistically significant differences were noted on global cognitive functioning (full-scale IQ) and P300 latency. In all cases the results were lower (as regards cognitive function) with higher spike frequency and this was in line with Jost et al. ${ }^{(9)}$. 


\section{CONCLUSION}

Interictal epileptiform EEG discharge had an additional effect on cognitive function especially, if generalized and if it was of high frequency. This effect might be often underestimated and might accumulate, and have a severe cognitive impact. Therefore, treatment of epileptic patients should put in concern reduction or even treatment of IEDs as controlling of these IED lead to improvement of cognition.

\section{REFERENCES}

1. Megiddo I, Colson A, Chisholm D et al. (2016): Health and economic benefits of public financing of epilepsy treatment in India: An agent-based simulation model. Epilepsia Official Journal of the International League Against Epilepsy, 57 (3): 464-474.

2. Jorge G, Jose $\mathbf{T}$ (2005): Understanding the burden of epilepsy in Latin America: A systematic review of its prevalence and incidence, 66 (1-3): 63.

3. Dodrill C (2004): Neuropsychological effects of seizures. Epilepsy Behav., 5(1): S21-S24.

4. Aldenkamp A, Arends J, OverwegPlandsoen W et al.(2001): Acute cognitive effects of nonconvulsive difficult-to-detect epileptic seizures and epileptiform electroencephalographic discharges. J Child Neurol., 16:119-123.

5. Menlove L, Reilly C (2015): Memory in children with epilepsy: A systematic review. Seizure, 25:126-35.

6. Binnie CD (2003): Cognitive impairment during epileptiform discharges: is it ever justifiable to treat the EEG? Lancet Neuro.1, 2:725-730.

7. Niedermeyer E, Lopes da Silva F (2005): Electroencephalography: basic principles, clinical applications, and related fields. Lippincott Williams \& Wilkins, Philadelphia, PA. pp: 256-280.

8. Aldenkamp A, Arends J (2004a): The relative influence of epileptic EEG discharges, short nonconvulsive seizures and type of epilepsy on cognitive function. Epilepsia, 45:54-63.
9. Jost N, Saskia E, Danielle M et al. (2012): The cognitive effects of interictal epileptiform EEG discharges and short non-convulsive epileptic seizure. Epilepsia, 53(6): 1051-59.

10. O'Leary SD, Burns TG, Borden KA (2006): Performance of children with epilepsy and normal age-matched controls on the WISC-III. Child Neuropsychol., 12:173-180.

11. Aldenkamp A, Beitler $\mathrm{J}$, Arends $\mathrm{J}$ et al. (2005): Acute effects of subclinical epileptiform EEG discharges on cognitive activation. Funct Neurol., 20:23-28.

12. Harinder J (2007): “Cerebral palsy: Interictal epileptiform discharges and cognitive impairment”, Clin Neurol Neurosurg, 109 (7): 549-552.

13. Shaymaa J, Zaid A, Mazin M (2012): Treatment of Subclinical Epileptic Discharges Affects Cognitive Functions in Epileptic Patients. Fac Med Baghdad, 54 (1): 112-7.

14. Ronit M (2005): "Treatment of interictal epileptiform discharges can improve behavior in children with behavioral problems and epilepsy", The Journal of Pediatrics, 146 (1): 112-11.

15. Hirokazu O (2010): 'Treatment of benign focal epilepsies in children: When and how should be treated', Brain Dev., 115 (32): 11651169 .

16. Krasniqi $S$, Neziri B, Islami $H$, Bauer $S$ (2010): 'Carbamazepine and lamotrigine plasma concentrations in epileptic patients during optimising therapy', Med Arh., 64(2):80-3.

17. Smith J (2005): 'EEG in the diagnosis, classification, and management of patients with epilepsy. J Neurol Neurosurg Psychiatry,76: ii2-ii7

18. Aldenkamp AP, Overweg J, Gutter TH et al. (1996): Effect of epilepsy, seizures and epileptiform EEG-discharges on cognitive function. Acta Neurol Scand., 93:253-259.

19. Jennifer I, Philip S, David W (2005): Neuropsychological correlates of electroencephalograms in children with epilepsy. Epilepsy Research, 64:49-62.

20. Dodrill C (1992): Neuropsychological aspects of epilepsy. Psychiatr. Clin. North Am., 15: 383-394. 